\title{
Sistem Kendali Sliding Roof untuk Smarthome Berbasis Internet of Things
}

\author{
Fachrul Muhammad ${ }^{1}$, Elfizon ${ }^{2}$ \\ ${ }^{1}$ Universitas Negeri Padang \\ Jl. Prof Dr. Hamka Air Tawar, Padang Indonesia \\ Fachrulm247@gmail.com1 ${ }^{1}$ elfizon24@gmail.com ${ }^{2}$
}

\begin{abstract}
The development of current technology can be utilized in daily life, one of which is opening and closing the roof. Currently, a home design that is being developed is a sliding roof. Which is an automatic roof open and close system. This sliding roof can be used for drying clothes and also for air circulation and light, the air quality in the house is not humid in the presence of sunlight. The purpose of this final project aims to design a sliding roof control using NodeMCU as a microcontroller and the google assistant application as a tool to provide government, water sensors as a water detector and power supply as a source. The roof can be opened and closed using the google assistant application without the influence of the water sensor, the data received from the google assistant is processed and processed by NodeMCU, after the data is received and processed, the data is used as a reference for controlling the motor that functions as a roof mover, roof will close automatically when the water sensor is exposed to water, the sensor will function when the roof is open. From the test and analysis results, the sliding roof control operates in accordance with the given rules. As long as the system is connected to a stable Wi-Fi network, there will be no problems with this system.
\end{abstract}

Keywords - NodeMCU, Google Assintant, Sliding roof, Water sensor.

Abstrak-Perkembangan teknologi saat ini bisa dimanfaatkan dalam kehidupan sehari-hari salah satunya yaitu buka-tutup atap. Saat ini desain rumah yang sedang dikembangkan yaitu sliding roof yang merupakan sistem buka-tutup atap otomatis. Sliding roof ini dapat dimanfaatkan untuk penjemuran pakaian dan juga untuk sirkulasi udara beserta cahaya kualitas udara di dalam rumah tidak lembab dengan adanya cahaya matahari. Tujuan tugas akhir ini memiliki tujuan merancang pengendalian sliding roof menggunakan NodeMCU sebagai Microcontroller dan aplikasi google assintant sebagai alat untuk memberi perintah, sensor air sebagai pendeteksi air dan catu daya sebagai sumber. Atap dapat dibuka-tutup menggunakan aplikasi google assintant tanpa dipengaruhi oleh sensor air dan data-data yang dikirimkan oleh google assintant akan diproses oleh NodeMCU. Setelah data diproses, data ini akan digunakan sebagai rujukan untuk mengendalikan motor yang berfungsi sebagai penggerak atap, atap akan menutup secara otomatis ketika sensor air terkena air, sensor hanya akan berfungsi ketika dalam keadaan atap terbuka. Selagi system terkoneksi dengan Wifi dalam keadaan stabil, tidak akan terjadi system error. Dari hasil pengujian dan analisa, pengendalian sliding roof beroperasi sesuai dengan tujuan dari penelitian. Selama sistem terhubung dengan jaringan Wifi secara stabil.

Kata kunci-NodeMCU, Google Assistant, Sliding roof, Sensor Air.

\section{Pendahuluan}

Kemajuan teknologi saat ini sudah berkembang dengan sangat pesat sehingga harus bisa dipelajari dan dimanfaatkan dalam penerapan di kehidupan sehari-hari. Salah satu contohnya adalah Otomatisasi, yangmana otomatisasi ini merupakan perangkat tambahan yang sistem kerja yang bekerja lebih sederhana, praktis dan efisien. Otomatisasi mampu pempersingkat proses dan memberikan tingkat ketelitian yang tinggi [1]. Smarthome merupakan contoh pengaplikasian otomatisasi yang sering ditemui dan sudah banyak dikembangkan.

Internet of Things (IoT) merupakan struktur dari sistem dimana objek pengguna disediakan dengan identitas eksekutif dan kemampuan untuk memindahkan data melalui jaringan tanpa memerlukan dua arah interaksi .[2] Pada zaman ini, luas tanah pada daerah perkotaan untuk dibuat rumah cenderung sangat sempit dan rumah-rumah yang dibangun biasanya memiliki desain minimalis. Seiring berkembangnya teknologi dan menjadi ilmu pengetahuan, beberapa orang mulai mengkreasikan desain rumah yang lebih nyaman dan canggih walau memiliki desain minimalis dengan memanfaatkan teknologi. Salah satunya adalah dengan pemanfaatan sliding roof. Mencuci pakaian merupakan salah satu kegiatan rumah tangga yang sering dilakukan dalam kehidupan masyarakat, agar pakaian yang dijemur terhindar basah akibat hujan maka diperlukan alat pengendali atap otomatis. [3] Pada rumah minimalis biasanya sulit untuk sinar matahari masuk kedalam rumah karena desain rumah minimalis biasanya berdempetan seperti didaerah perkotaan. Kurangnya sinar matahari, bisa menyebabkan kurangnya sirkulasi udara dan sistem pencahayaan alami yang minim. Pada era modern ini para arsitek mulai mengembangkan desain rumah modern agar 
mendapatkan tempat tinggal yang nyaman ditinggali dengan meggabngkan teknologi didalamya.

Desain rumah yang mulai dikembangkan untuk rumah minimalis disini adalah sliding roof, yang merupakan sistem buka-tutup atap otomatis dan tidak membutuhkan lahan. Sliding roof dapat dimanfaatkan untuk penjemuran pakaian dan untuk sirkulasi udara berserta pencahayaan alami agar di dalam rumah tidak lembab. Solusi dari penelitian ini adalah memberikan ruangan jemur yang atap pada ruangan tersebut bisa dibuka-tutup menggunakan sliding roof otomatis dan juga berfungsi untuk pencahayaan alami. Penelitian tugas akhir "Sistem otomasi atap bangunan pada gudang pengering jagung berbasis arduino uno. Pengembangan yang dapat dilakukan dari penelitain ini adalah dengan mengganti arduino dengan NodeMCU dan menghubungkannya dengan Internet of Things sehingga alat bisa bekerja dengan smartphone[4].

Berdasarkan penelitian sebelumnya penulis berinovasi membuat perancangan sistem kendali Sliding roof dengan berbasis Internet of Things.

\section{NodeMCU}

NodeMCU merupakan sebuah platform IoT bersifat open source.[5] NodeMCU adalah gabungan dari ESP8266 ke sebuah board yang komplit dengan akses terhadap WiFi dan juga chip komunikasi USB to Serial, untuk pemograman hanya memerlukan eksitensi kabel data mikro USB. NodeMCu disini berfungsi sebagai kontroler utama.

\section{Motor DC}

Motor dc atau motor arus searah merupakan suatu mesin yang digunakan untuk mengubah tenaga listrik menjadi energi kinetik atau gerak. Dengan menggunkan motor dc berfungsi untuk menggerakkan atap.[6]

\section{Driver BTS7960}

Driver BS7960 ini digunakan unutk memudahkan dalam menentukan arah putaran motor dc, pada driver ini terdapat rangkaian full H-bridge. IC BTS7960 berfungsi untuk perlindugan saat terjadi panas.

\section{Sensor Air}

Rangkaian pada sensor air dirancang untuk mendeteksi air, hal ini terjadi karena rangakaian sensor air menggunakan komponen resistor sebagai komponen utama. Saat papan sensor terkena air akan terjadi proses elektrolisasi yang dapat menghantar arus listrik.

\section{Metode}

Pada bab ini akan membahas tentang perancangan hardware dan software.

\section{A. Blok Diagram}

Blok diagram merupakan serangkaian blok-blok yang dihubungkan oleh garis-garis yang menjelaskan tentang diagram pembuatan dan perancangan alat secara ringkas melaui blok diagram tersebut. Secara umum komponen yang digunakan adalah NodeMCU, driver BTS7960, motor dc dan sensor air. Gambar dibawah ini merupakan blok diagram penelitian.

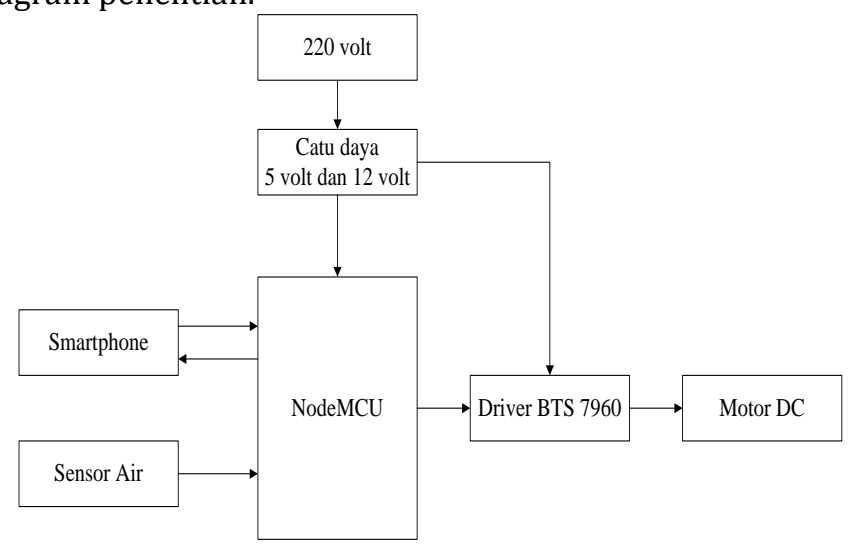

Gambar 1. Blok diagram

Berikut penjelasan dari blok diagram yang ada pada gambar 1.

1. NodeMCU berfungsi sebagai pengolah data dari sensor air dan smartphone, yang akan diteruskan ke aktuator yaitu motor dc.

2. Catu daya berfungsi sebagai penyupply daya ke NodeMCU dan driver BTS7960. Pada sistem ini catu daya yang digunakan yaitu 5 volt 12 volt.

3. Sensor air berfungsi sebagai pendeteksi air yang mana ketika sensor aktif maka data dikirim dan diproses oleh NodeMCU.

4. Smartphone dalam rangkaian ini berfungsi sebagai pemberi sinyal masukan yang akan di teruskan dan di proses oleh NodeMCU.

5. Driver BTS7960 adalah penghubung antara NodeMCU dan motor dc, driver ini memiliki rangkaian H-bridge yang berfungsi sebagai membalik arah putaran motor dc.

6. Motor dc berfungsi sebagai aktuator untuk menggerakkan atap.



Gambar 2. Rangkaian Keseluruhan 


\section{B. Perancangan Mekanik alat}

Peracangan mekanik merupakan suatu proses atau tahapaan dalam pembuatan tugas akhir ini. Perancangan ini bertujuan mengurangi kesalahan serta agar memudahkan dalam membuat alat sehingga mendapatkan hasil yang maksimal. Bentuk mekanik yang dirancangan merupakan miniatur rumah dengan ukuran $65 \mathrm{~cm} \mathrm{x} 30 \mathrm{~cm}$ x $30 \mathrm{~cm}$. rancangan mekaniknya dapat dilihat pada gambar 2 .

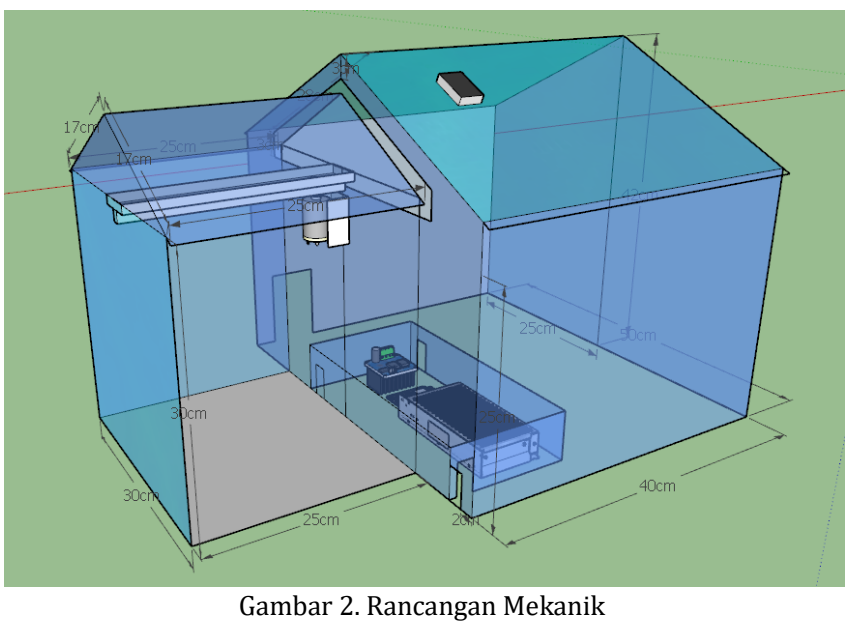

\section{Flowchart}

Cara kerja alat ini dikelakan melalui suatu bagan yang menunjukkan urutan suatu program. Flowchart sistem kendali sliding roof untuk smarthome dapat dilihat pada gambar 3.

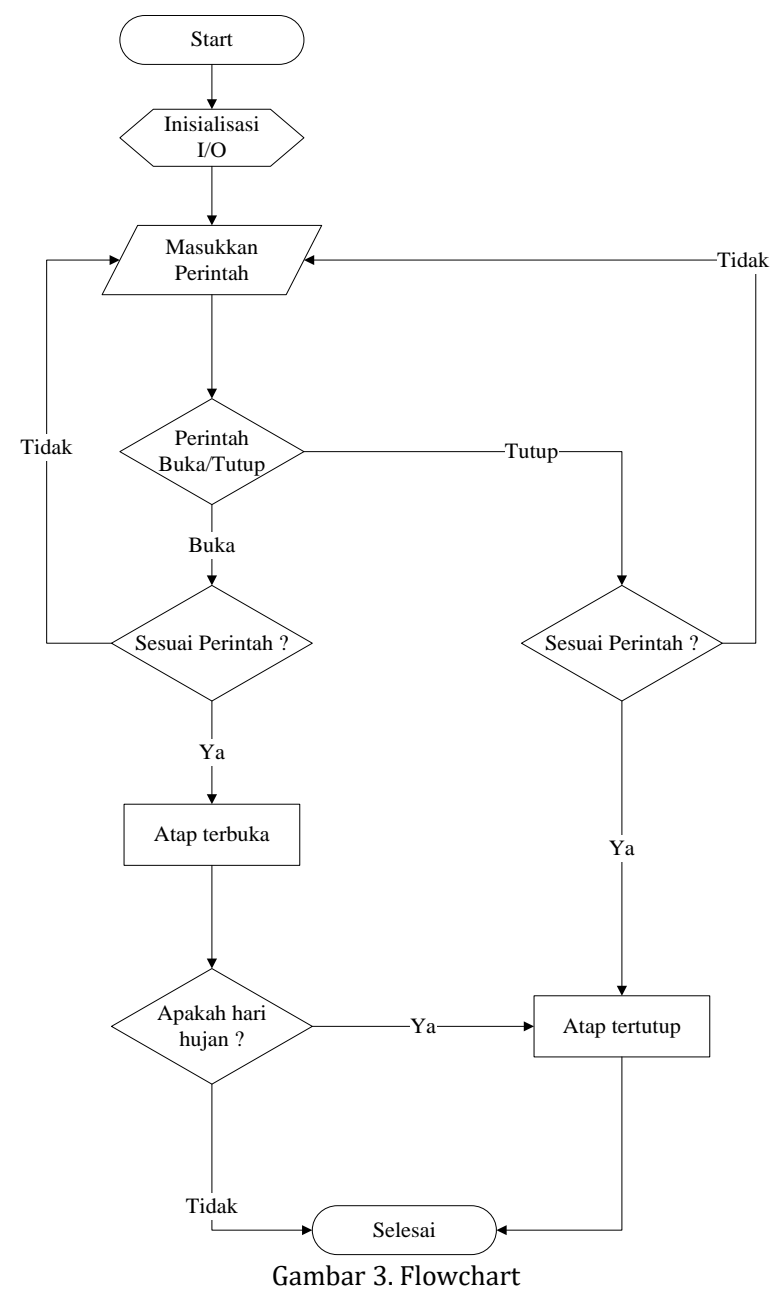

\section{HASIL DAN PEMBAHASAN}

Pada hasil bagian ini akan dilakukan beberapa pegujian dan analisa pada input dan output. Pengujian dan analisa ini bertujuan untuk mengetahui sensor dapat berfungsi dengan baik sebagai input sesuai dengan yang diingikan. Bentuk mekanik alat dapat dilihat pada gambar 9 .



\section{Pengujian Sensor Air}

Pengujian ini untuk meneliti apakah sensor dapat bekerja dan bisa memerima perintah dengan lancar. Pada 
pengujian ini menggunakan NodeMCU sebagai pengolah data yang berupa mengubah analog ke digital. Pengukuran dilakukan dengan mengukur tegangan dan tahanan menggunakan avometer dengan cara menghubungkan kedua ujung dari avometer ke kutub sensor air.

Tabel I. Pengujian Sensor Air

\begin{tabular}{|c|c|c|c|}
\hline $\begin{array}{c}\text { Kondisi Sensor } \\
\text { Air }\end{array}$ & Tegangan & Tahanan & Logika Port \\
\hline Tidak ada air & 4.8 volt & Tak hingga & High (1) \\
\hline Ada air (hujan) & 1.4 volt & $488 \Omega$ & Low (0) \\
\hline
\end{tabular}

Pada tabel I menunjukkan hasil pengukuran resistansi pada papan sensor air dapat ditarik kesimpulan yaitu semakin sedikit air yang ditetes atau disemprotkan ke papan sensor maka tegangan dan resistansinya kan semakin kecil juga begitu juga sebaliknya semakin banyak air yang ada papan sensor maka resistansi nya akan semakin tinggi juga.

\section{Pengujian Motor}

Tabel II. Data pengukuran pengujian motor

\begin{tabular}{|c|c|c|c|}
\hline Kondisi Motor & Tegangan & Arus & Logika Port \\
\hline Aktif & 1.6 volt & $0.3 \mathrm{~A}$ & High (1) \\
\hline Tidak aktif & 0 volt & $0 \mathrm{~A}$ & Low $(0)$ \\
\hline
\end{tabular}

Berdasarkan hasil pengujian dari tabel II ditunjukkan bahwa nilai tegangan motor saat bekerja yaitu 1.6 volt, Pada pemograman digunakan pin PWM dan diproses oleh driver BTS7960 hal ini terjadi karena untuk menurunkan kecepatan motor. Penurunan tegangan motor bertujuan unutk menurunkan kecepatan motor saat membuka dan menutup atap.

\section{Pengujian Respon Google Assitant}

Tabel III. Respon google assintant

\begin{tabular}{|c|c|c|c|}
\hline Percobaan & $\begin{array}{l}\text { Respon google } \\
\text { assistant (Time) }\end{array}$ & $\begin{array}{l}\text { Respon Output } \\
\text { (Time) }\end{array}$ & Perintah \\
\hline 1 & $2 \mathrm{~s}$ & $4 \mathrm{~s}$ & Open \\
\hline 2 & $3 \mathrm{~s}$ & $4 \mathrm{~s}$ & Close \\
\hline 3 & $4 \mathrm{~s}$ & $5 \mathrm{~s}$ & Open \\
\hline 4 & $3 \mathrm{~s}$ & $4 \mathrm{~s}$ & Close \\
\hline 5 & $3 \mathrm{~s}$ & $4 \mathrm{~s}$ & Open \\
\hline 6 & $2 \mathrm{~s}$ & $4 \mathrm{~s}$ & Close \\
\hline
\end{tabular}

Pada keadaan pertama, unutk melakukan pengujian alat keseluruhan yaitu dengan menghubungkan alat ke sumber, lalu mengunggu beberapa detik agar NodeMCU terhubung dengan jaringan Wi-Fi. Pada tabel III menunjukkan respon berapa lama google assistant memberikan balasan atas perintah yang telah diberikan, rata-rata lama waktu respon dari google assistant yaitu 2-4 detik hal ini terjadi dipengaruhi oleh stabil atau tidaknya jaringan Wi-Fi. Respon output yang dimaksud adalah berapa lama waktu yang dibutuhkan agar atap terbuka atau tertutup.

\section{Penutup}

Berdasarkan hasil pengujian, dapat disimpulkan bahwa alat pengontrol buka-tutup atap berbasis Internet of Things dapat bekerja dengan baik sesuai yang diinginkan. Atap akan terbuka-tutup jika perintah yang telah ditentukan sebelumnya, dan sensor akan aktif hanya dalam kondisi atap terbuka, yang akan memutup secara otomatis jika terjadi hujan.

\section{REFERENSI}

A. K. Dewi, M. S. Hadi, and S. Anwar, "Sistem Atap Rumah Otomatis pada Smarthome dengan Menggunakan Arduino," J. Teknol. dan Sist. Komput., vol. 5, no. 1, p. 43, 2017, doi: 10.14710/jtsiskom.5.1.2017.43-48.

[2] A. Junaidi, "Internet of Things, Sejarah, Teknologi Dan Penerapannya," J. Ilm. Teknol. Inf., vol. I, no. AUGUST 2015, pp. 62-66, 2016.

[3] E. Mufida dan A. Abas, "Alat Pengendali Atap Jemuran Otomatis dengan Sensor Cahaya dan Sensor Air Berbasiskan Mikrokontroler ATmega16," Informatics Educ. Prof., vol. 1, no. 2, p. 234377, 2017.

[4] N. Damastuti, "Sistem Otomasi Atap Bangunan pada Gudang Pengeringan Jagung Berbasis Arduino Uno," eNARODROID, vol. 2, no. 1, 2016.

[5] Wicaksono, M. Fajar. "Implementasi Modul Wifi NodeMCU ESP8266 Untuk Smart Home”, Jurusan Teknik Komputer, UNIKOM, 2017.

[6] Ogata, K. 1993. Teknik Kontrol Automatic. Jakarta : Erlangga

[7] Asy'ari, Mochammad \& Sugianto. 2014. Rancang Bangun Atap Jemuran Otomatis untuk Smarthome Berbasis IOT.

[8] Novriadi. 2014. "Rancang Bangun dan Pembuatan Alat Home Security Sistem menggunakan SMS Gateway Bebasis Android". Tugas Akhir : Universitas Negeri Padang.

[9] A. G. Butarbutar et al., "Rancang Bangun Prototype Buka Tutup Atap Otomatis Untuk Proses Pengeringan Dan Penyimpanan Gabah Menggunakan Wemos D1 Mini".2017.

[10] W. Wilianto and A. Kurniawan, "Sejarah, Cara Kerja Dan Manfaat Internet of Things," 2018.

\section{Biodata Penulis}

Fachrul Muhammad dilahirkan di Lubuk Sikaping, 7 Agustus 1997, menyelesaikan Program studi DIV Teknik Elektro Industri Pada jurusan Teknik Elektro Fakultas Teknik Universitas Negeri Padang.

Elfizon, M.Pd.T, dilahirkan di Lima puluh kota, 25 Agustus 1985, menyelesaikan S1 di Universitas Negeri Padang dan S2 di Universitas Negeri Padang, Staf pengajar tetap di jurusan Teknik Elektro Fakultas Teknik Universitas Negeri Padang sampai sekarang. 